\title{
The Influence of Self-Concept on Perceived Value in Apparel Brand Adoption Behavior - Based on Research Data from Hangzhou, China
}

\author{
Yiling Zhang ${ }^{1,2}$, Xiangyang Bian ${ }^{1}$, Aijuan Cao ${ }^{1,3}$, \& Ziyin $\mathrm{Yu}^{2}$ \\ ${ }^{1}$ College of Fashion and Design, Donghua University, Shanghai, China \\ ${ }^{2}$ Applied Technical School, Jiaxing University, Jiaxing, China \\ ${ }^{3}$ Highfashion Womenwear Institute of Hangzhou Vocational \& Technical College, Hangzhou, China \\ Correspondence: Xiangyang Bian, College of Fashion and Design, Donghua University, Shanghai, NO.1882, \\ West Yan-an Road, 200051, China. Tel: 86-21-6237-3978. E-mail: bianxy@dhu.edu.cn
}

Received: March 29, 2018

Accepted: May 3, $2018 \quad$ Online Published: June 22, 2018

doi:10.5539/ass.v14n7p47

URL: https://doi.org/10.5539/ass.v14n7p47

\begin{abstract}
In consumer society, consumers intend to pay more attention to the brand culture, symbolic meaning, brand value and the brand-self fit when they choose apparel or brand. By self-concept as breakthrough point, this paper analyze the interactive relationship between self-concept and perceived value. The empirical results show that: During the apparel brand adoption process, using functional value, social value, emotional value, cognitive value, and situational value to evaluate the perceived value of Chinese consumers is feasible and effective; The ideal self and actual self interact with each other, and also can affect the formation of perceived value; Through the perceived value of brand, self-concept has a significant impact on the apparel brand adoption behavior. With more homogenous and competitive apparel, enterprises should give thorough consideration to enhance the objective brand value, as well as to reduce the gap between consumer perceived value and brand value.
\end{abstract}

Keywords: self-concept, perceived value, apparel consumption, brand adoption

As the saying clothing is regarded as the second skin of human beings. The importance of clothing in modern society and culture has become increasingly prominent. The research on consumer dress and consumption psychology has increasingly become the focus of marketing, consumer behavior and social psychology, attracting much attention from scholars and entrepreneurs. Stone (1965) once described: when we dress ourselves, we are also transmitting ourselves. And when we wear clothes, we are also dressing up or transmitting messages to audiences who are bound to respond effectively to our existing selves. (Stone, 1965, p. 230) Therefore, appearance management in daily life should not be underestimated. Dressing, as the primary means of appearance management, is considered to be a "symbolic language" that transmits a series of complex information. Especially after entering the consumer society, more and more people began to pay attention to their dressing to improve their self-image as well as the information that clothing can convey. In this case, clothing consumption not only satisfies people's physiological needs but also interprets their psychological needs. On the one hand, people build self-image and pursue individuality through clothing, and they make use of clothing brands \& products to realize the externalization of self-image. On the other hand, people seek to use the clothing brand for identity construction, maintain and reinforce a particular social identity that they identify themselves as, or isolate themselves from a certain group. That is the reason why people accept ultra value of brand clothing. The key issues that will be discussed in this paper are ways that consumers choose among numerous beautiful and well-known apparel brands, whether self-concept play an important role in brand selection, and the relation of self-concept to brand perceived value and consumer decision-making.

\section{Literature Review and Research Hypothesis}

\subsection{Research Status}

Customer Perceived Value (CPV) (Liu \& Chou, 2005, pp. 82-84; Fan, 2003, pp. 41-45), which was proposed in 1990 's is refers to the consumer balance between the perceive benefit and the cost of products or services. CPV is the overall evaluation of the product and service utility. It is also subjective consumer cognition of product value and service value, which is different from the objective value. It is known that perceived value has the following two characteristics. On the one hand, value is influenced by many factors such as consumer's 
subjective cognition, social cultural context, self-regulation, group norm, objective value of goods and service level. On the other hand, perceived value varies from person to person. Different consumers have distinct perceived value for the same brand product. By theoretical analysis and empirical research, scholars have come to realize that consumption behavior is not only determined by the actual value of commodity, but more restricted by the brand image and emotion perceived by consumers (Levy, 1981, pp. 49-61). Therefore, with the increasing importance of brand value in the study of consumers' consumption behavior, the research on value perception is also deepening.

Self-Concept was first proposed by Harvard psychologist William James (1890) in The Principles of Psychology, but it began to be concerned by consumer behavior researchers until 1960s. In 1982, Sirgy (Sirgy, 1982, p. 90) gave a systematic explanation of self-concept, which is a concept of consumer self, that has a holographic projection connection with consumer behavior. Also, he pointed out that consumer behavior can be predicted by studying the reflection relationship. Meanwhile, self-concept is the product of society. It interprets itself from the social perspective. Social culture plays a decisive role in the content and structure of self-concept. Different consumers follow their cultural norms in social context to play their roles. In short, self-concept is the process of individual socialization, which is closely related to its social role. (Cang \& Cai, 2008, pp. 496-500) Everyone plays multiple roles in the social relations, and consumers need different products and brands to express themselves in many aspects when they change their social role or status.

\subsection{Research Theoretical Model and Hypothesis}

At present, the research on the perceived value in the process of customer value theory development mainly focused on two aspects. Firstly, perceived value dimension model was put forward that analyses consumers' perceptions of product from dimensions "gains and losses". Sheth, Newman \& Gross (Sheth, Newman, \& Gross, 1991, pp. 188-192) proposed five dimensional model: functional value, social value, emotional value, cognitive value, situational value. It provided a perfect measurement table to the empirical research on the perceived value of the future. After that, Parasuraman (Parasuraman, 2000) divided perceived value into acquisition value, transaction value, use value and redemption value. Kotler (2000) divided perceived value into the total customer value (product, service, personnel and image value) and total customer cost (currency, time, energy, etc.). Sweeny \& Soutar [10] (Sweeny \& Soutar, 2001, pp. 203-220) demonstrated that the perceived value has 4 aspects: emotional value, social value, functional price value and functional quality value. Secondly, Monreeand \& Shnan (1985) and Dodds et al (1991) proposed that perceived value affects purchase intention, where many researchers have done empirical research on it recently. Therefore, this article come up with hypothesis $1 \mathrm{a}, 1 \mathrm{~b}$, $1 \mathrm{c}, 1 \mathrm{~d}$ and $1 \mathrm{e}$ according to the article in Sheth et al. (1991) that described the basis of perceived value dimension model: The positive association between perceived value and brand selection during consumers' apparel brand choice. Hypothetical relationships are shown in Figure 1. The functional value refers to the objective utility of brand products or services; social value is the value of products or services that satisfy consumers in order to conform with social group norms or show social status; emotional value is the consumer emotional response to a particular product or service, such as nostalgia, joy, sadness, satisfaction, etc. Perceived value refers to the novelty of a product or a brand; Situational value is denoted as the social or functional value that a product or service can be provided with certain situations.

At the same time, studies have found that consumer self-concept will affect their weighing gains and losses of the product or service, which in turn affect one's selection and use. Meanwhile, consumers also enhance their self-concept through the consumption performance for specific products. Consumption behaviorists Levy also stressed that the contemporary consumer in the process of brand choice has not just commodity function oriented, their behavior is largely affected by symbolic significance contained in commodity (Ying, 2006, p. 7), namely consumption decisions are influenced by self and the consistency of brand image perception. In addition, some researchers further studied this idea, and it was widely confirmed. In this paper, we propose hypothesis $2 \mathrm{a}, 2 \mathrm{~b}, 2 \mathrm{c}$, $2 \mathrm{~d}$ and $2 \mathrm{e}$ : the consistency of ego and brand influences the formation of consumer perceived value, and they are positively correlated with each other. The hypothetical relationships are shown in Figure 1.

Therefore, after combing the existing perceived value and self concept, based on the 5 dimensional model of perceived value of Sheth (1991), this paper proposes a theoretical model of self concept to perceived value (see Figure 1). 


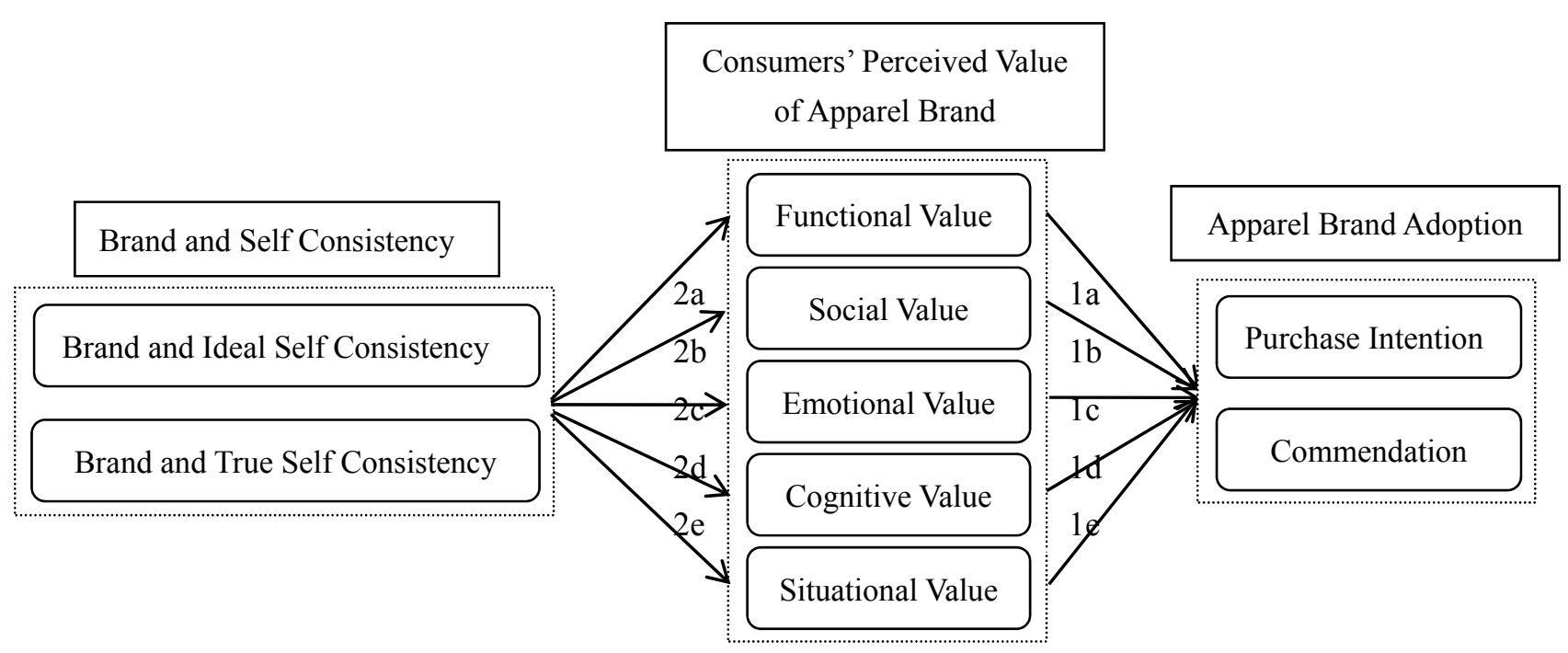

Figure 1. Theoretical model

\section{Empirical Analysis}

In order to ensure a credible and effective research, this paper uses the scale from the domestic and foreign scholars. It combines current situation in online apparel consumption and design a questionnaire adapted to the industry under the guidance of experts. The content of the questionnaire is divided into two parts: the basic information survey and the study variable measurement. The design of test index is based on the Liken 5 point scale, and the data is analyzed with SPSS19.0 and AMOS17.0.

\subsection{Survey Sample Analysis}

In this study, a total of 822 questionnaires were distributed randomly through online and offline, and 601 valid questionnaires were collected. The recovery rate was $73.11 \%$, and the basic information of the sample was shown in table 1 . The age of the interviewees in the sample was under 35 years old. Those with bachelor's degree accounted for $56.1 \%$ of the total number. The occupation is mainly students and ordinary staff, and the monthly income is mainly concentrated in RMB 4000 - 12000.

Table 1. Profile of Respondents

\begin{tabular}{|c|c|c|c|c|c|c|c|}
\hline Indivic & Information & Frequency & Ratio/\% & Individua & nformation & Frequency & Ratio/\% \\
\hline & & & & & Student & 147 & 24.5 \\
\hline & & & & & General Staff & 259 & 43.1 \\
\hline Gender & Male & 275 & 45.8 & Occunation & General Manager & 75 & 125 \\
\hline & Female & 326 & 54.2 & uccupation & Senior Manager / & 75 & 12.5 \\
\hline & & & & & private Owner & 44 & 1.3 \\
\hline & & & & & Others & & \\
\hline & Under 25 & 179 & 29.8 & & & & \\
\hline & $25-30$ & 173 & 28.8 & & $<4000$ & 63 & 10.5 \\
\hline Age & $31-35$ & 165 & 27.5 & Monthly & $4000-8000$ & 201 & 33.4 \\
\hline & $36-40$ & 55 & 01 & Income / yuan & $8001-12000$ & 254 & 42.3 \\
\hline & Over 40 & 29 & 4.8 & & $>12000$ & 83 & 13.8 \\
\hline & Junior college or & & & & Street Side Shop & 149 & 24.8 \\
\hline & below & 215 & 35.8 & & Shopping Mall & 212 & 35.3 \\
\hline Educational & Undergraduate & 337 & 56.1 & Purchase Places & Network Shop & 209 & 34.8 \\
\hline & Master's degree or & 49 & 8.1 & & Purchasing & 14 & 2.3 \\
\hline & above & & & & Others & 17 & 2.8 \\
\hline
\end{tabular}

\subsection{Factor Analysis, Reliability Validity Test and Correlation Analysis}

$\mathrm{KMO}$ and Bartlett sphere tests were performed on the sample data to verify whether the sample data was suitable for factor analysis. The result is: KMO value is 0.812 , while Bartlett sphere test is significant $(\mathrm{p}=0.000)$. The sample data is suitable for factor analysis based on the factor analysis standard. 
Table 2. Factor Analysis and Validity Analysis of Perceived Value

\begin{tabular}{|c|c|c|c|c|c|c|}
\hline \multirow{2}{*}{ Variable(Xi) } & \multicolumn{5}{|c|}{ Factor Loading } & \multirow{2}{*}{ Eigenvalue } \\
\hline & $\mathrm{X} 1$ & $\mathrm{X} 2$ & $\mathrm{X} 3$ & $\mathrm{X} 4$ & $\mathrm{X} 5$ & \\
\hline \multirow{5}{*}{$\mathrm{X} 1$} & 0.642 & & & & & \multirow{5}{*}{2.570} \\
\hline & 0.721 & & & & & \\
\hline & 0.755 & & & & & \\
\hline & 0.520 & & & & & \\
\hline & 0.549 & & & & & \\
\hline \multirow{4}{*}{$\mathrm{X} 2$} & & 0.619 & & & & \multirow{4}{*}{3.013} \\
\hline & & 0.653 & & & & \\
\hline & & 0.760 & & & & \\
\hline & & 0.646 & & & & \\
\hline \multirow{5}{*}{$\mathrm{X} 3$} & & & 0.628 & & & \multirow{5}{*}{2.671} \\
\hline & & & 0.796 & & & \\
\hline & & & 0.738 & & & \\
\hline & & & 0.756 & & & \\
\hline & & & 0.639 & & & \\
\hline \multirow{4}{*}{$\mathrm{X} 4$} & & & & 0.521 & & \multirow{4}{*}{3.033} \\
\hline & & & & 0.642 & & \\
\hline & & & & 0.601 & & \\
\hline & & & & 0.644 & & \\
\hline \multirow{4}{*}{ X5 } & & & & & 0.530 & \multirow{4}{*}{3.054} \\
\hline & & & & & 0.736 & \\
\hline & & & & & 0.741 & \\
\hline & & & & & 0.527 & \\
\hline
\end{tabular}

Based on the suitability test of factor analysis, the principal component method is used to extract the factor. The principle of factor extraction is that the feature value should be greater than 1 . The maximum variance rotation method is adopted, with default convergence number 25 , and the principal component matrix after factor analysis is presented in Table 2. It can be shown from Table 2, the result of factor extraction is consistent with the dimension division of the perceived value of clothing brand in the original scale. The factor represents the functional value, social value, emotional value, cognitive value and situational value, their characteristic values were $2.570,3.013,2.671,3.033,3.054$ respectively, which are greater than 1 . The cumulative amount reached $79.511 \%$, indicating that 5 factors explain the perceived value to an acceptable level, and measurement the scale has good validity.

At the same time, the correlation analysis was used to analyze the data of this survey based on the reliability and validity of the questionnaire. The results were shown in Table 3.

Table 3. Mean, Standard Deviation, Correlation Coefficient and Reliability Coefficient of Variables

\begin{tabular}{|c|c|c|c|c|c|c|c|c|c|}
\hline Variable & M & SD & $\begin{array}{c}1 \\
\text { Self and } \\
\text { Brand } \\
\text { Consistency }\end{array}$ & $\begin{array}{c}2 \\
\text { Functional } \\
\text { Value }\end{array}$ & $\begin{array}{c}3 \\
\text { Social } \\
\text { Value }\end{array}$ & $\begin{array}{c}4 \\
\text { Emotional } \\
\text { Value }\end{array}$ & $\begin{array}{c}5 \\
\text { Cognitive } \\
\text { Value }\end{array}$ & $\begin{array}{c}6 \\
\text { Situational } \\
\text { Value }\end{array}$ & $\begin{array}{c}7 \\
\text { Brand } \\
\text { Adoption }\end{array}$ \\
\hline 1 & 3.716 & 0.869 & 1.000 & & & & & & \\
\hline 2 & 3.615 & 0.843 & $0.287 * *$ & 1.000 & & & & & \\
\hline 3 & 3.210 & 0.874 & $0.391 * *$ & $0.376^{* *}$ & 1.000 & & & & \\
\hline 4 & 3.722 & 0.851 & $0.108 * *$ & $0.389 * *$ & $0.312 * *$ & 1.000 & & & \\
\hline 5 & 3.241 & 0.803 & $0.267 * *$ & $0.358 * *$ & $0.329 * *$ & $0.327 * *$ & 1.000 & & \\
\hline 6 & 3.613 & 0.861 & $0.342 * *$ & $0.365^{* *}$ & $0.318^{* *}$ & $0.330 * *$ & $0.276^{* *}$ & 1.000 & \\
\hline 7 & 4.012 & 0.845 & $0.249 * *$ & $0.341 * *$ & $0.401 * *$ & $0.462 * *$ & $0.418 * *$ & $0.328 * *$ & 1.000 \\
\hline
\end{tabular}

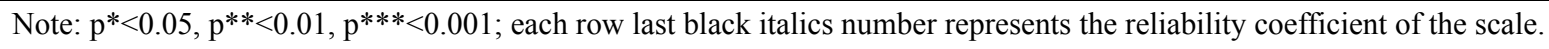




\subsection{Hypothesis Test}

Using the SEM method, the results for the assumptions proposed above are verified by structural variance model: The test statistics is $3.11\left(\chi^{2 / \mathrm{df}}\right)$ that is less than 5 , and it is acceptable based on the study by Wheaton et. al (1977). Therefore, this statistical indicators meet the requirements. The RMSEA value is 0.042 . According to Steiger's (1990) point of view, the RMSEA below 0.05 is a very good fitting, so the index is also in accordance with the statistical requirements. In addition, GFI value is 0.910 , AGFI value is 0.876 , IFI value is 0.923 , CFI value is 0.915 . Based on Bentler's (1992) proposal, the model has satisfactory fitting degree if GFI is greater than or equal to 0.85 , given CFI is greater than or equal to 0.90 . Therefore, the preliminary test results of the original model are better.

Table 4. Path Coefficient and Significance Test Results

\begin{tabular}{|c|c|c|c|c|}
\hline \multicolumn{2}{|c|}{ Path Relation } & \multirow{2}{*}{$\begin{array}{c}\text { Normalized Path Coefficient } \\
0.17\end{array}$} & \multirow{2}{*}{$\begin{array}{c}\text { Saliency Probability } \\
* * *\end{array}$} & \multirow{2}{*}{$\begin{array}{c}\text { Hypothetical Support } \\
\text { Fully Support }\end{array}$} \\
\hline $\mathrm{H} 2 \mathrm{a}$ & $\mathrm{X} 1 \rightarrow \mathrm{X} 2$ & & & \\
\hline $\mathrm{H} 2 \mathrm{~b}$ & $\mathrm{X} 1 \rightarrow \mathrm{X} 3$ & 0.41 & $* * *$ & Fully Support \\
\hline $\mathrm{H} 2 \mathrm{c}$ & $\mathrm{X} 1 \rightarrow \mathrm{X} 4$ & 0.14 & * & Weak Support \\
\hline $\mathrm{H} 2 \mathrm{~d}$ & $\mathrm{X} 1 \rightarrow \mathrm{X} 5$ & 0.19 & $* * *$ & Fully Support \\
\hline $\mathrm{H} 2 \mathrm{e}$ & $\mathrm{X} 1 \rightarrow \mathrm{X} 6$ & 0.37 & $* * *$ & Fully Support \\
\hline H1a & $\mathrm{X} 1 \rightarrow \mathrm{X} 7$ & 0.33 & $* * *$ & Fully Support \\
\hline $\mathrm{H} 1 \mathrm{~b}$ & $\mathrm{X} 1 \rightarrow \mathrm{X} 7$ & 0.41 & $* * *$ & Fully Support \\
\hline $\mathrm{H} 1 \mathrm{c}$ & $\mathrm{X} 1 \rightarrow \mathrm{X} 7$ & 0.35 & $* * *$ & Fully Support \\
\hline H1d & $\mathrm{X} 1 \rightarrow \mathrm{X} 7$ & 0.21 & $* * *$ & Fully Support \\
\hline H1e & $\mathrm{X} 1 \rightarrow \mathrm{X} 7$ & 0.51 & $* * *$ & Fully Support \\
\hline \multicolumn{2}{|c|}{ Fitting Index } & \multicolumn{3}{|c|}{$\begin{array}{c}\chi 2 / \mathrm{df}=3.11, \mathrm{RMSEA}=0.042, \mathrm{GFI}=0.910 \\
\mathrm{AGFI}=0.876, \mathrm{IFI}=0.923, \mathrm{CFI}=0.915\end{array}$} \\
\hline
\end{tabular}

Note: $* \mathrm{p}<0.05, * * \mathrm{p}<0.01, * * * \mathrm{p}<0.001$

\section{Conclusion}

From the perspective of self-concept, this paper empirically analyzes the influence of brand and self fit on brand adoption, based on perceived value as a mediator variable. All the hypothetical paths in the theoretical model have been verified: The normalized path coefficients of $2 \mathrm{a}, 2 \mathrm{~b}, 2 \mathrm{c}, 2 \mathrm{~d}$ and $2 \mathrm{e}$ are $0.17,0.41,0.14,0.19$ and 0.37 , which indicate that the self-concept formed by the interaction between the ideal self and the real self, has a positive impact on perceived value and brand adoption behavior. And the social value and the situation value are more prominent, and the emotional value is weak. At the same time, the normalized path coefficients of $1 \mathrm{a}, 1 \mathrm{~b}$, $1 \mathrm{c}, 1 \mathrm{~d}$ and $1 \mathrm{e}$ are $0.33,0.41,0.35,0.21$ and 0.51 , validating that 5 value dimensions positively and significantly affect their brand adoption decisions; and perceived value plays an intermediary role between the self fit brand and the adoption decision, in which the situation value and the social value are more significant. In addition, investigation of this study also found that consumers, especially those who have certain culture and status in society not only considered the functional value, emotional value, cognitive value but also paid attention to social value and the situational value when making clothing brand adopted decision.

Based on the research conclusion, this paper proposes four corresponding marketing strategies. First, the rapid development of modern information technology has accelerated the formation of global market. As a result, brand competition has become increasingly fierce. The enterprises should not only enhance the brand value from the perspective of their own but also from consumers' perspective to survive. They should consider the perceived value perception of consumers and the perceived value they need to provide. Second, the ascension of brand value is not achieved overnight, but follow the long-term and steady pace. The brand value can be effectively realized by constantly reducing the gap among consumer perceived value, brand value provided by enterprises, and brand value positioning. Third, self-concept exists in consumers' psychological activities and has a profound influence on consumers' cognitive psychology and consumption behavior. When consumers choose clothes and brands, they have attached great importance to the symbolic information conveyed by clothing. They hope to convey their psychological state, image, status and situational meaning through clothing. Therefore, enterprises should take full consideration of the self-image and demands of target groups in brand planning. Fourth, clothing 
enterprises can also set up exclusive community or exclusive brand community for brand target people, as well as provide consumers with platforms to communicate with similar consumer groups and guide them to rational consumption.

\section{Acknowledgments}

The authors would like to thank Donghua University, Applied Technical School, Jiaxing University. Also, many thanks for the supporting of the project of Scientific research project of Zhejiang Education Department (00717030AW) and the project of Special subject for reform and innovation of Talent Cultivation Mode of JiaXing University. Meanwhile, thanks to the editor and the readers of Asian Social Science.

\section{References}

Cang, P., \& Cai, W. (2008). The Empirical Study on the Model of Fashion Marketing Strategy and the Comprise of Brand Equity. Journal of Donghua University (Natural Science), 32(4), 496-500. https://doi.org/10.3969/j.issn.1671-0444.2008.04.024

Fan, X. C. (2003). Study on Competitiveness of Service Firms: A Customer Perceived Value Perspective. Nankai Business Review, 6(6), 41-45. https://doi.org/10.3969/j.issn.1008-3448.2003.06.009

Levy, S. J. (1981). Intepreting Consumer Mythology: A Structural Approach to Consumer Behavior. Journal of Marketing, 45, 49-61. https://doi.org/10.2307/1251541

Liu, Y., \& Chou, X. Y. (2005). Review of customer value theory. Modern Management Science, (5), 82-84. https://doi.org/10.3969/j.issn.1007-368X.05:034

Parasueaman. (2000). Reflections on gaining competitive advantage through customer value. Journal of the Academy of Marketing Science, 25(2).

Sheth, J., Newman, B., \& Gross, B. (1991). Consumption Values and Market Choices-Theory and Applications (pp. 188-192). Cincinnati: South-Western.

Sirgy, M. J. (1982). Self-image/product-image congruity and purchase motivation: A role playing experiment. Proceedings of the American Psychological Association-Consumer Psychology Division (p. 90).

Stone, G. P. (1965). Appearance and the self: A slightly revised version (p. 230). New York: John Wiley \& Sons.

Sweeny, C. J., \& Soutar. (2001). Customer perceived value: the development to a multiple item scale. Journal of Retailing, 77(2), 203-220. https://doi.org/10.1016/S0022-4359(01)00041-0

Ying, A. L. (2006). The Application of Self-Concept in Consumer Behavior research of High Education Products. Nanjing University of Aeronautics and Astronautics, 7. https://doi.org/10.7666/d.d051916

\section{Copyrights}

Copyright for this article is retained by the author(s), with first publication rights granted to the journal.

This is an open-access article distributed under the terms and conditions of the Creative Commons Attribution license (http://creativecommons.org/licenses/by/4.0/). 